\title{
Exploitation of Business Models for Deep Renovation ${ }^{\dagger}$
}

\author{
Simona D'Oca 1,*, Annarita Ferrante 2, Peter Op 't Veld 1, Nicolas Peraudeau ${ }^{3}$, Christoph Peters 4, \\ Roberta Pernetti ${ }^{5}$, Oana Schippers-Trifan ${ }^{6}$ and Regis Decorme ${ }^{7}$
}

1 Huygen Engineers \& Consultants, Urmonderbaan 22, 6167 RD Geleen, The Netherlands

University of Bologna, Viale del Risorgimento 2, 40136 Bologna BO, Italy

3 DOWEL Management, 100 Rue Albert Caquot, 06560 Sophia Antipolis, France

4 LIMA Association, Passatge Cot, 13, 08198 Sant Cugat del Vallès, Barcelona, Spain

EURAC Research, Viale Druso Drususallee, 1, 39100 Bozen, Südtirol, Italy

DEMO Consultants, Delftechpark 10, 2628 XH Delft, The Netherlands

R2M Solution, Les Galeries de Beaumon, D2085 06330 Roquefort les Pins, Spain

* Correspondence: s.doca@huygen.net

† Presented at the Sustainable Places 2019 (SP 2019), Sardinia, Italy, 5-7 June 2019.

Published: 23 July 2019

\begin{abstract}
In this workshop, we discussed the exploitation experiences gathered in some relevant H2020 projects on deep renovation: TripleA-reno, ProGETonE, P2Endure, 4rinEU, STUNNING, and TURNkey Retrofit. Directives and practical insights that support the experimentation with exploitation strategies in EU-funded projects will be elaborated as outcome of the workshop.
\end{abstract}

Keywords: exploitation plan; business models; deep renovation

\section{Introduction}

The ability to envision user needs and integrate them into a project value proposition is a vehicle towards more effective and sustainable business models for deep renovation practices. However, many projects still struggle to involve the user in their business model design method.

In spite of the clarified potential for business models underpinning energy efficiency measures to generate profit in the clean energy market, the uptake of deep renovation practices is not flourishing to its full potential. Several barriers have been highlighted that still distress the market uptake of energy efficiency measures, among which the need for long-term capital for often comparatively small investments, the strain of measuring and distributing the energy savings due to deep renovation practices, as well as general lack of familiarity among consumers with renovation concepts.

The dispute here, with even the economically sound business models, is that, for the user, there is an apparent lack of attractiveness for deep renovations, that goes beyond the mere financial savings or economical profitability offered by the investment. A conceivable resolution to upsurge the market uptake of renovation practices, is therefore the design of business models, which focus on the multiple environmental, social and financial benefits deep renovation practices might deliver for the different stakeholders involved in the process. Benefits, that are sometimes hard to monetise and generalize among the involved user groups, as they do not always resonate to the provider/receiver of these values equally, but on the contrary can develop contrasting interests.

Therefore, in this report, we are summarizing the contributions of several H2020 projects on deep renovation, including: TripleA-reno [1], ProGETonE [2], P2Endure [3], 4rinEU [4], STUNNING [5], and TURNkey Retrofit [6].

This, in a way to explore what type of deep renovation business models exist in practice, and how they actually are impacting the EU market uptake of deep renovation practices. 


\section{TripleA-reno}

Objective of the TripleA-reno project is to develop a gamified platform that serves a service and tool for key stakeholders involved in the renovation journey, to facilitate understanding, communication exchange, decision making, practices and guarantee high efficient performance (Figure 1).

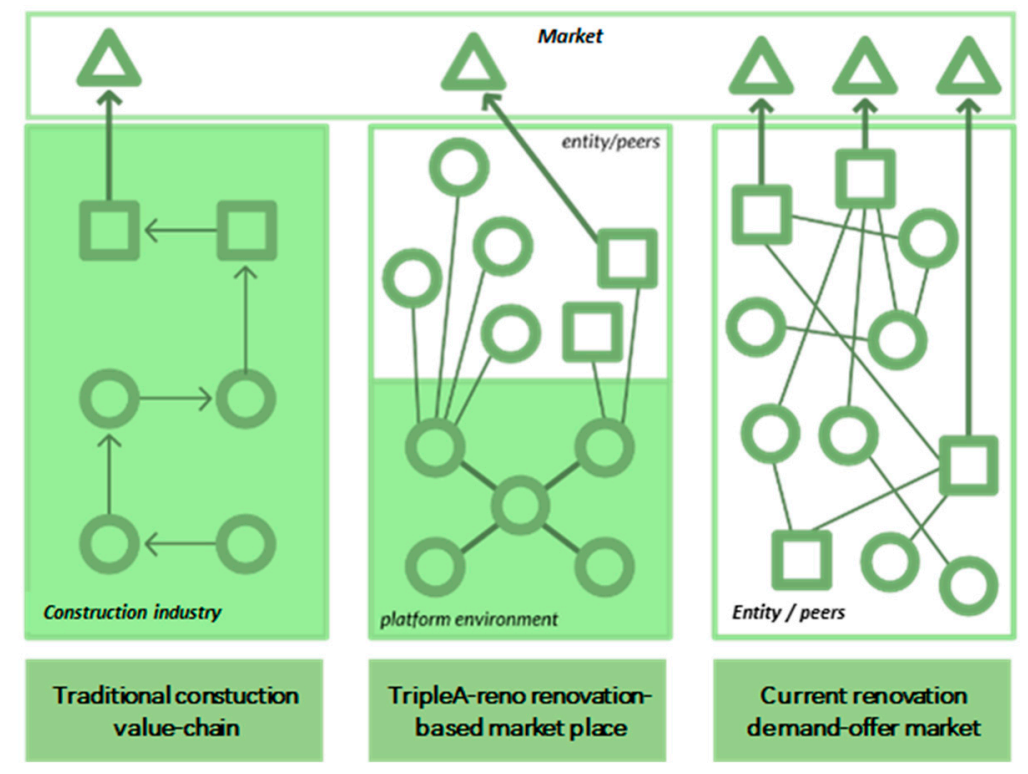

Figure 1. Illustration of the TripleA-reno envisioned renovation market place (business model), compared to the traditional value-chain and demand-offer market model.

The TripleA-reno platform also gives the chance to small suppliers to have a bigger audience (that they wouldn't reach on their own). In TripleA-reno users can leave reviews about the suppliers they worked with. Suppliers can therefore focus more on quality (get a good review) than on traditional marketing for themselves (they will be found via the platform). The TripleA-reno platform must behave as a tool whose primary feature is to empower and enable independent exchanges to happen in the renovation market and to enable customers' (construction industry, entities, peers) usage, experience, appreciation, and retainment.

The TripleA-reno platform also offers the renovation end user much more choice for less work (they don't have to find all these companies to compare themselves) compared to traditional renovations experiences. The first radical mindset and operational innovation in TripleA-reno, when facing the platform service and product design, is to leave behind the idea of a linear business models, with a service provider from one side and a service recipient (or customer) from the other. The traditional business model canvas (BMC) remains indeed a great tool to represent linear aspects of businesses, but fails in modelling emerging ecosystem-based and multi-sided platform models where different players, have different customer journeys, including different motivations to join, needs, and visions to co-participate in the whole value creation of the process.

What we are currently trying to shape by leveraging on customer journey is indeed not (just) a business model, but a platform-shaping strategy. This customer journey includes all the stages users go through when interacting with a company, from looking up the products or services to buying products online, calling customer service and posting on social media about the company. For TripleA-reno, the customer journey is the path suppliers and users follow in discovering, using and reviewing the platform. In a broader perspective, every interaction with TripleA-reno is part of their customer journey of deep renovation. When users make a decision or buy a product or service, that's just the tip of the iceberg. The same counts for home owners and supplier start using a platform. In the specific case of TripleA-reno, the customer journey contains all the relevant steps leading up to the renovation. These correspond to the functionalities of the platform in the three levels: (1) design, (2) renovation, 
(3) after renovation. However, the customer journey doesn't stop after renovating. The TripleA-reno platform also maintains insights and services to the home owners and after renovating.

\section{ProGETonE}

The unique selling point (value proposition) of the Pro-GET-onE project is the distinctive integration between energy deep renovation techniques and seismic retrofitting actions: the GET system. This "X-factor" aims at solving construction and safety problems within nZE (nearly Zero Energy) retrofitting, focusing on users' priorities and expectations. The project idea is based on the unprecedented integration of different technologies to achieve a multi-benefit (energy, structural, functional) approach by a closer integration between energy and non-energy related benefits in order to optimise the efficiency, attractiveness and marketability of the solution (Figure 2).

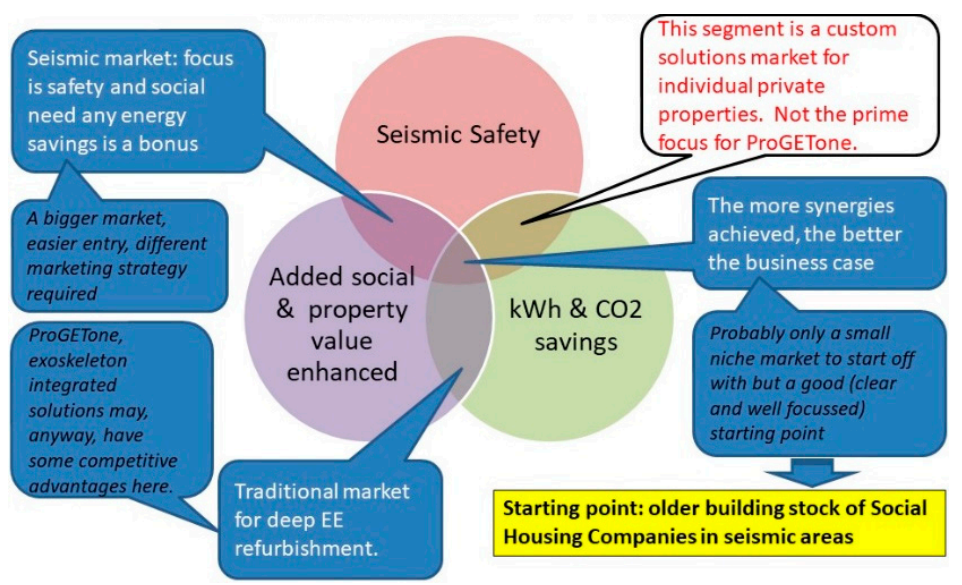

Figure 2. Illustration of the ProGEtonE market and business case.

The prime customers of the GET system are the public and private property owners who are directly responsible for the management of their building stock and maintenance of their assets, particularly those in areas of seismic risk with aging housing stock in need of renovation. Their challenge is the lack of available funding for building programmes. The opportunity is the cost effectiveness of the integrated solution. The strength of the ProGETonE solution is that it addresses all their priorities (seismic, social, economic, environmental). These customers will buy whenever they are able to clearly appreciate and justify that investment in prevention is so much cheaper than recovery and repair after seismic events. They may also buy, when they have available budget, simply because the GET system will be the best possible solution in many cases. The main barrier [7] is the lack of awareness of the possibilities and the potential of the integrated solution and the consequent and logical distrust of and lack of confidence in the performance and longevity of the results. This main threat is the tendency to do patchwork repairs due to budgetary limitations and/or political expediency. These prime clients are unlikely to discover the GET system by themselves. Instead they are most likely to contact buildings professionals (architects, surveyors, engineers and planners) to find solutions that meet their management and maintenance requirements. For this reason, these buildings sector professionals or practitioners also form an important part of the target audience. It is good strategy to tailor the messages about the GET solutions to the interest and concerns of each group focussing, for example on design, costs, structural characteristics and impact on the surrounding areas respectively. The exploitable market for this integrated solution involves three factors:

- a suitable building stock in need of refurbishment,

- owned by a client/s that is/are sensitive to the added social value

- in geographical area with the need for seismic resilience

Where all three factors coincide a strong business case can be demonstrated because the integrated solution is significantly cheaper than the sum of individual solutions for seismic resilience and energy 
efficiency. In addition to the enhanced seismic resilience, improved energy performance and associated reduction in emissions of $\mathrm{CO}_{2}$ and other pollutants, the solution offers multiple social benefits and also enhances the value of the property. Further work needs to be done to quantify these social and capital related benefits in order to strengthen the business case for the integrated GET solution. There may also be viable markets where two out of three factors coincide.

At this stage in the ProGETone project development it is not possible to provide definitive answers to these key questions because work is still going on in all aspects of the project. However, tentative answers can be provided in order to set the scene and start of visualise the path to follow for business plan development.

\section{P2Endure: District Alliance for Deep Renovation ('Local E-Marketplace')}

A large number of innovative solutions for deep renovation have become available from various EU-funded research projects and beyond. What is urgently needed is to increase the scale of adoption through the integration of these solutions (processes and ICT tools) and to upscale the implementation of such retrofit solutions within large-scale commercial projects. At the moment, there is still a lack of solid empirical evidence that such innovations deliver the expected performance, both energetically and financially. But also, the right environment where both, the needed advisory (technical and financial) instruments and the link between government-market and users is made available. Within P2Endure we propose the concept of a local district renovation platform: a place where demand meets supply, where solution providers are connected with (local) suppliers to ensure a smooth collaboration between the stakeholders and an efficient execution of a renovation project at district scale (Figure 3). In short, a place where alliances are created, and where advisory tools and technical assistance services are available to facilitate the process (offering the needed information on the needed retrofit measures to finance the investment).

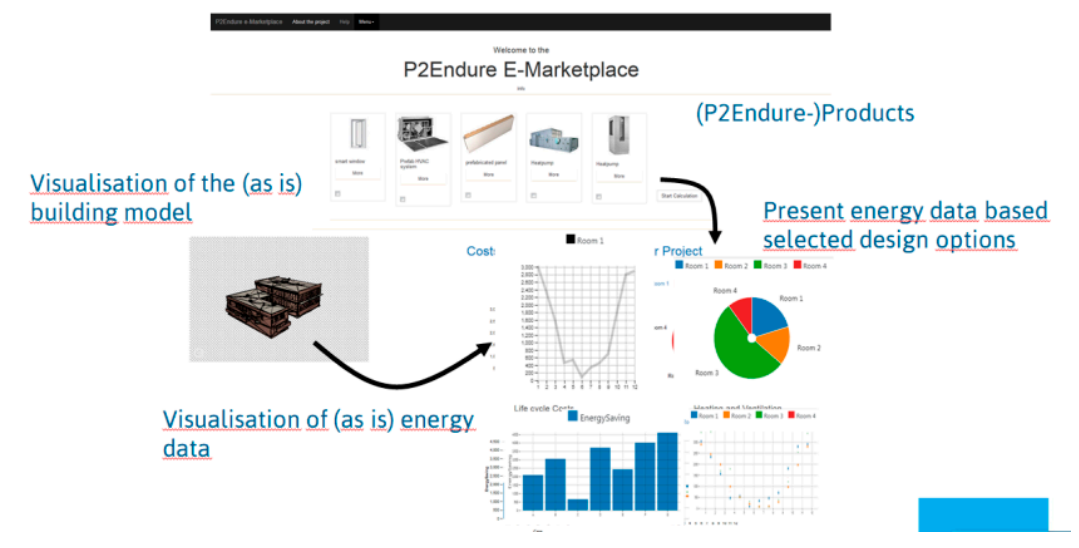

Figure 3. Illustration of the P2EndurE local e-market place and business case.

Besides the functionalities of a conventional e-marketplace, the P2Endure concept entails the integration of the parametric modeller (energy calculation tool within P2Endure) and of other micro-services making the platform more complete ('holistic offer') and flexible at the same time, as this responds to the demand of providing clear insights into the whole renovation process in terms of costs, energy and time savings. In addition, comparison possibilities between traditional renovation and P2Endure plug\&play-renovation, and information related to wider benefits such as, health and safety are to be visualised in the platform. The local district alliance platform is aimed at, both creating the proper environment that ensures an active involvement of all local stakeholders ('stimulate interest of collaboration") with regards to their district renovations plans, and providing the necessary vehicle for innovative local SMEs to enlarge and upscale their local and national market shares. In the last year of the project, we aim at testing and implementing the district alliance collaboration model and district renovation planning concept. This testing activity will be carried out in conjunction with the live demonstration case in Tilburg (NL). In the 't Reit district in Tilburg, The Netherlands, the P2Endure 
approach for standardised deep renovation feasibility assessment will be discussed with the stakeholders. A variety of stakeholders have already confirmed their participation, including:

- Demand side: local housing corporation, private owners and House Owners Association;

- Governmental: Municipality of Tilburg

- Representatives and educational: Local training associations;

- Market side: Local solution providers (e.g., façade manufacturers), financial experts and advisers.

At the same time, the P2Endure local e-market place provides a common environment for all involved parties allowing them to develop/design cost-optimal strategies, not only looking at the investments costs of the renovation but also taking into account:

- the whole lifecycle costs;

- overview of the building stock/ building typologies and energy labels in order to set up proper renovation strategies; and

- available financial advice to facilitate access to sources of financing the renovation.

\section{4RinEU}

The level of confidence of investors in case of renovation is usually quite low because of several uncertainties throughout the process: reliability of energy and economic savings, construction failures, risk associated to the application of technologies and methodologies. Indeed, the actual investments are lower than potential because there are no reliable references that assess such uncertainties.

In order to cope this issue, the project 4 RinEU is defining solutions to balance investment and performance targets by developing robust, cost-effective, tailorable, deep renovation technology packages supported by usable methodologies, feeding into reliable business models (Figure 4). Such models will make investors (single owner, multi-owners, social housing organizations, large real estates, developers) more confident in all the renovation phases. One of the backbone of the project 4RinEU, is the Cost-Effectiveness Rating Tool (whose development is coordinated by SINTEF), which represents be a comprehensive reference to define reliable business models for deep renovation, including a detailed mapping of risks and failures associated to renovation packages applied within the project as well as their Life Cycle Costs.

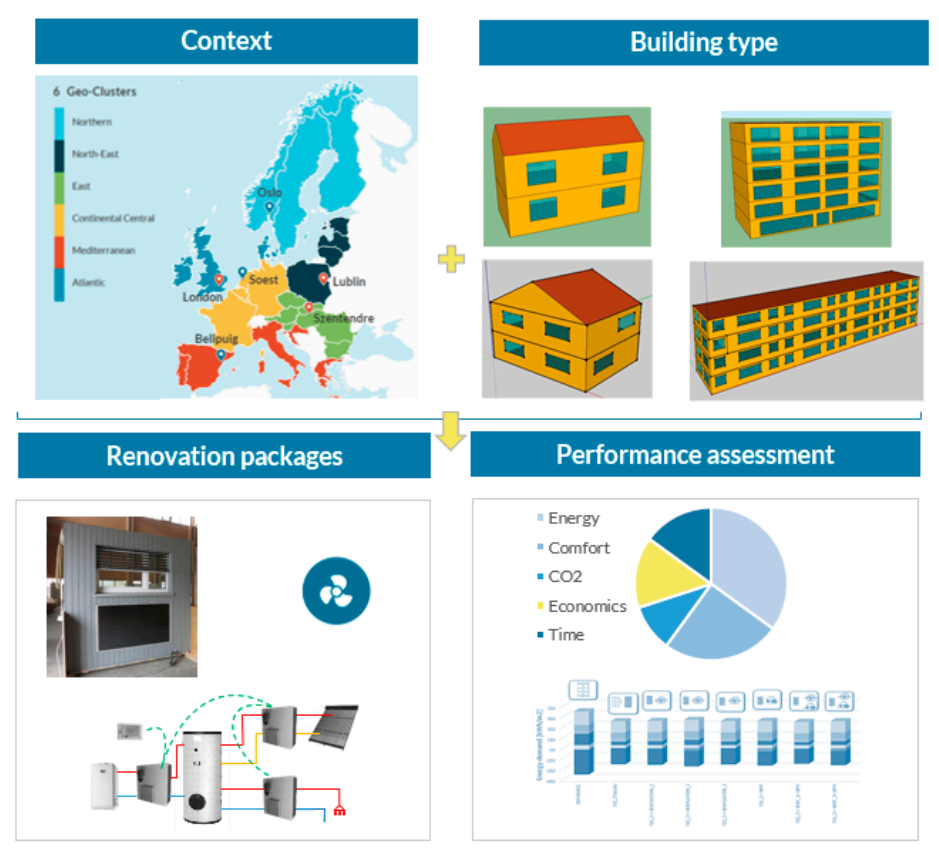

Figure 4. Workflow Cost-Effectiveness rating system of the 4rinEU project. 
The tool includes several results of the project, from the Key Performance indicators (KPIs) to compare the impact of the solutions, to the risk analysis of the technologies and the renovation packages. This tool represents one of the key elements for the exploitation of the project, since will enable the users to access the information and the results of the project structured according to the need of a renovation process. In particular, it includes as a background the database of KPIs evaluated for 4 different building typologies in 6 climate and legislative contexts among Europe (i.e., in the six EU Geo-clusters defined within the project) analysed for the proposed renovation packages.

The database includes 144 renovation package for each context and building type, composed by different variants of both solutions developed within 4 RinEU (i.e., prefabricated multi-functional façade, plug\&play energy hub, ceiling fan, sensible data handler) as well as commercial products available on the market (insulation, high efficiency boiler, photovoltaic and solar thermal panels). The user can access such information through defining the renovation priority (i.e., improving the comfort, the energy efficiency of the building, the $\mathrm{CO}_{2}$ emission, minimising the investment cost and/or the renovation time), the building type as well as the context. As a result, the tool offers support the decision-making process identifying the most suitable renovation packages and comparing the solutions in terms of performance indicators, highlighting cost, energy consumption, comfort conditions, renovation time and $\mathrm{CO}_{2}$ emission after application of the renovation package.

The stakeholders of the tool are investors, building owners and consultants that need a general overview of the potential impacts of an intervention package on the performance of the building they own or manage, in order to be aware of the cost and benefits of a renovation.

\section{STUNNING}

In Europe, 40 to $45 \%$ of energy consumption comes from buildings. Further $5-10 \%$ required for the manufacturing and transport of construction products and components. The building sector will be one of the key enablers to achieve EU objectives by 2050, as most of the energy savings required must come from existing buildings. Today, renovation rate is only at $1 \%$ while it should be at least $3 \%$.

STUNNING project highlights the main barriers to the renovation of the EU building stock, and find, analyse and promote sustainable European business models for the deep renovation of buildings. STUNNING partners developed an approach in three stages: first a refurbishment packages database was created with information on demonstrations or real cases in Europe; then barriers in renovation sectors was identified to promote the most promising business models and innovative case studies; finally a Knowledge Sharing Platform (KSP), called Renovation Hub, was developed to share relevant information among a stakeholder community composed of multiple types of actors (Figure 5).

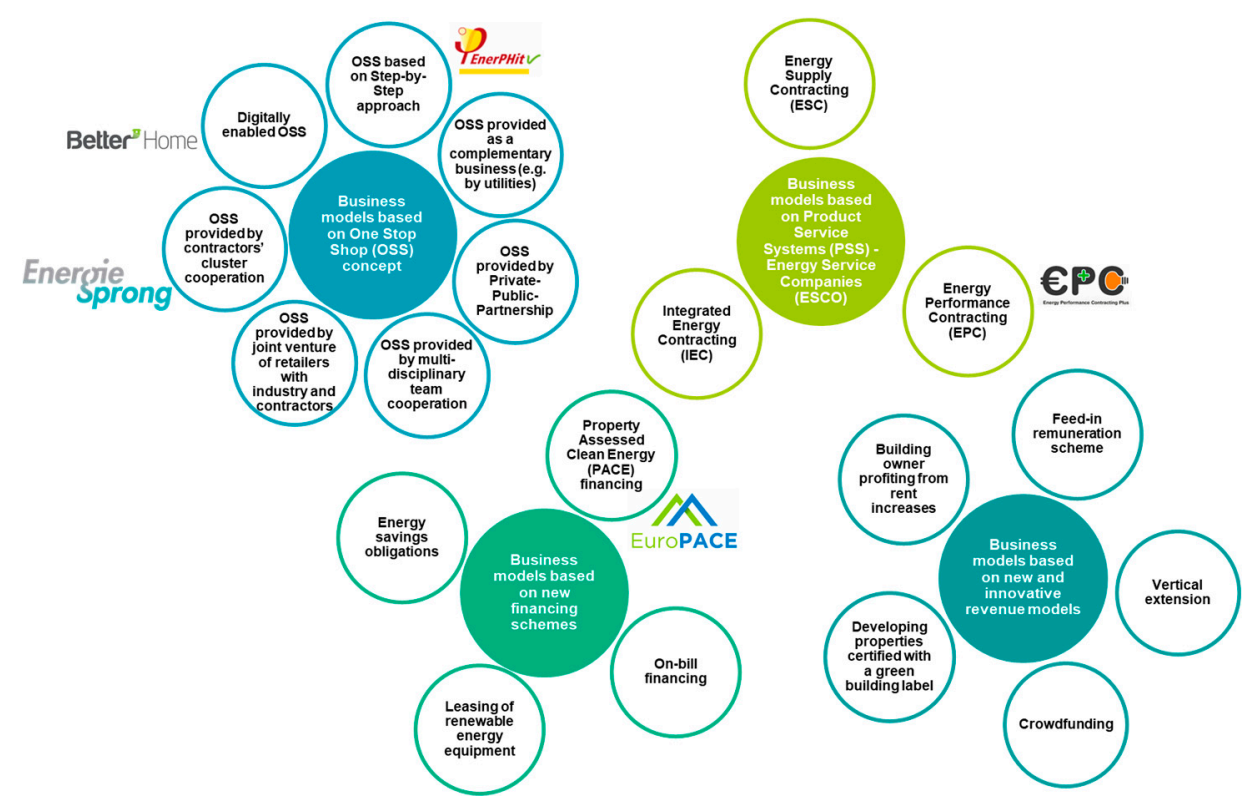

Figure 5. Business models illustrated in the STUNNING project by concrete examples. 
The review of existing or emerging technical solutions for building refurbishment focuses on integrated approach, i.e., combination of solutions implemented together to optimize energy efficiency. Different types of packages are being compared through economic indicators such as cost benefit analysis, based on real data (renovation cases) or demonstrations. These analyses demonstrated that most of the barriers to energy renovation are generally non-technical, and rather due to financing issue, a lack of information and acceptance by building owners and decision-makers, as well as missing skills from contractors and SMEs to innovate with new business models and change their habits. Facing these issues requires to develop a systemic, integrated and user-centered approach from design to operation, a coordinated approach involving all actors and increase fundamental research to find innovative business models as well as smart financing.

For business models, STUNNING provides analysis of innovative models for building refurbishment in Europe, based on One Stop Shop (OSS) concept (OSS provided by Private-Public Partnership, OSS based on Step-by-Step approach...), Product Service Systems and Energy Service Companies (Energy Supply Contracting, Energy Performance Contracting...), New financing schemes (Energy savings obligations, On-bill financing...), New and innovative revenue models (Vertical extension, Crowdfunding...).

All those business models are promoted through the Renovation Hub, webinars or own events. Results from business models' analyses show that models must move risk and financial expenses from owners to institutional investors or banks, but they must also highlight the non-energy benefits to decrease risk and payback time. Successful business model must be user-centered, focus on the multiple benefits of energy renovation, such as comfort and health after renovation, or develop collaboration models at all level of the value chain.

\section{TURNkey Retrofit}

For project promoters such as homeowners, the renovation process can be complicated, shaped by the ambiguity of the interventions to implement, combined with a lack of knowledge on existing solutions, as well as a lack of services to coordinate all required market actors involved in the renovation process. Achieving the full market potential of renovation calls for a paradigm shift, where both a more service-oriented supply-side and a deeper awareness on the demand-side play key roles, and where market offers go beyond energy performance to include a wider range of home improvement and support services (Figure 6).

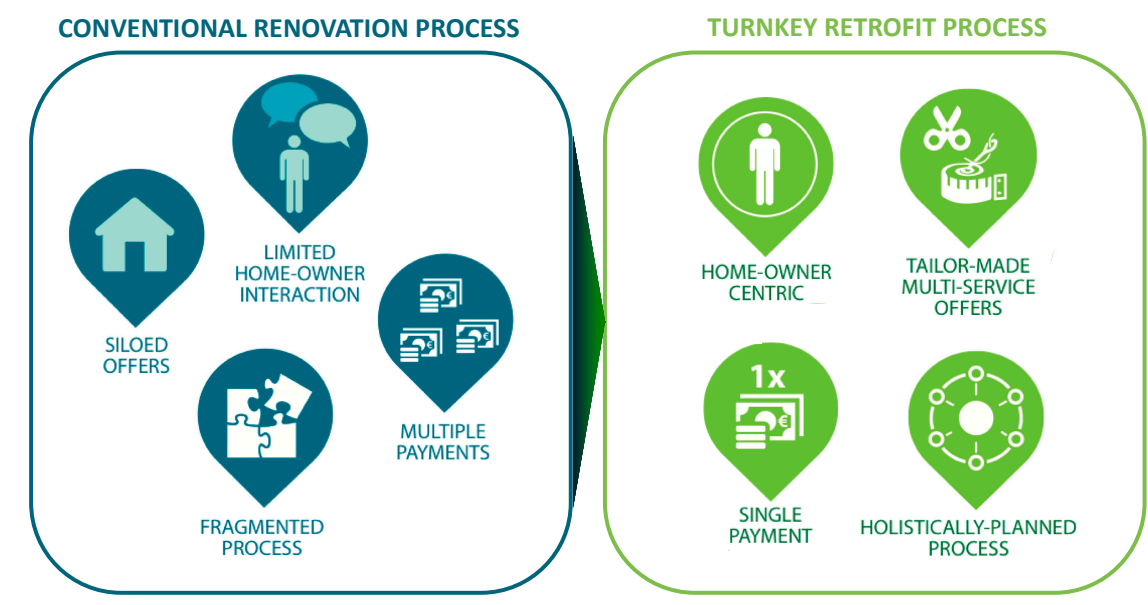

Figure 6. Conventional renovation process vs. integrated renovation process in TURNkey.

Such an approach will result in less-intrusive, better coordinated, more efficient and more attractive interventions. To tackle the above challenges, TURNkey RETROFIT will develop and replicate an integrated home renovation service which will be initially operated in 3 EU countries-France, Ireland and Spain. The TURNkey RETROFIT service will be developed as a home-owner-centric renovation journey, which will transform the complex and fragmented renovation process into a simple, 
straightforward and attractive process for the home-owner. It will include the initial technical and behavioural diagnosis, technical offer, contract development and agreement, structuring and provision of financial support, as well as the on-site coordination of works and quality assurance. It will be a service-oriented model where the home-owner is offered tailor-made solutions through the whole customer journey. The service will be accessible through a user-friendly digital platform and it will address drivers of building renovation that go beyond a desire to reduce energy bills and increase asset value, such as home improvement, increased comfort, enhanced health \& quality of life. The TURNkey RETROFIT service will be developed in particular through the integration and enrichment of 2 existing French services (Izigloo and Operene) targeted at single-family and multi-family housing renovation, respectively. Both of these integrated services are industry-driven and currently operated without public subsidies. Their business model will serve as the primary inspiration model for the TURNkey RETROFIT integrated service which will be improved and further developed in France and replicated in Ireland and the north of Spain (Basque country) by taking into account the local contexts.

\section{Lesson Learned and Action Planning}

A matching position is remarkable for the TripleA-reno, ProGETonE, P2Endure, 4rinEU, STUNNING, and TURNkey Retrofit cluster projects: the strong focus on marketing and customer needs. Analysis of all the data and insights available will give insights in best practices in renovations and will show the quality of the renovations. Because of the mediation role between stakeholders involved in the renovation process, the platforms have exponential potential of growth. Both minor service providers and dominant suppliers can join the development of the platform, in which they can take part via API's. This cooperation is foreseen changing the market for home renovations. This is consistent, for example, with the vision of TripleA-reno to make deep renovations attractive, acceptable and affordable. Platforms act as old-fashioned middlemen: they offer products and services based on their knowledge and the need of the end users.

This is the case of the P2Endure local e-market place. The platform takes care of the infrastructure and with that, makes it easy for suppliers and end users to access to innovative renovation technologies like for instance, the ProGETonE GET system. That's the way renovation platforms work as well: a middleman between the users (the home owners) and the suppliers (architects, engineers, contractors). Connecting, communicating, reinsuring (and motivating) throughout the renovation process (and after) is key, as highlighted by the STUNNING project. The biggest added value of a platform lies in the reduction of friction in the old supply-demand model. The renovation platform solves the friction of the user not knowing what to do before, during and after a renovation, while it solves friction for the suppliers as well: their instructions will be clearer and they will have the right tool to complete the job, as for TURNkey.

In conclusion, renovation platforms will provide a long term experience boost in the renovation journey, compared to the episodic touchpoint that might have occurred outside the platform. Further steps will be jointly taken by the cluster projects to form a Task Force on Platform-based renovation business models, that can be intrinsically valuable for a wide array of deep renovation actions in Europe at large.

Funding: These cluster projects have received separate funding from the European Union's Horizon 2020 research and innovation program under the following grant agreements: TripleA-reno: No. 784972, Pro-GET-OnE: No. 723747; P2Endure: No. 72339; 4RinEU: No. 723829; STUNNING: No. 768287; TURNkey RETROFIT: No. 839134.

Conflicts of Interest: The authors declare no conflict of interest.

\section{References}

1. TripleA-reno Website. Available online: https://triplea-reno.eu/ (accessed on 15 July 2019).

2. ProGETonE Website. Available online: https://www.progetone.eu/ (accessed on 15 July 2019).

3. P2Endure Website. Available online: https://www.p2endure-project.eu/en (accessed on 15 July 2019).

4. 4rinEU Website. Available online: http://4rineu.eu/ (accessed on 15 July 2019). 
5. STUNNING Website. Available online: https://www.stunning-project.eu/ (accessed on 15 July 2019).

6. TURNkey Website. Available online: https://cordis.europa.eu/project/rcn/222724/en (accessed on 15 July 2019).

7. D'Oca, S.; Ferrante, A.; Ferrer, C.; Pernetti, R.; Gralka, A.; Sebastian, R.; Veld, P. Technical, financial, and social barriers and challenges in deep building renovation: Integration of lessons learned from the H2020 cluster projects. Buildings 2018, 8, 174, doi:10.3390/buildings8120174.

(C) 2019 by the authors. Licensee MDPI, Basel, Switzerland. This article is an open access article distributed under the terms and conditions of the Creative Commons Attribution (CC BY) license (http://creativecommons.org/licenses/by/4.0/). 